\title{
CRITICAL SIZES OF STANDING NUCLEAR BURNING WAVES IN SYSTEMS WITH EXTERNAL CONTROL
}

\author{
Yu.Ya. Leleko, V.V. Gann \\ Scientific and Technical Complex "Nuclear Fuel Cycle”, Center for Reactor Core Design, \\ NSC “Kharkov Institute of Physics and Technology", \\ Kharkiv, Ukraine \\ E-mail: makswell@kipt.kharkov.ua
}

The theory of standing waves of nuclear combustion in reactors having a flat, cylindrical or spherical shape of the core is developed. A spherical standing wave occurs when nuclear burning propagates radially from the center of the sphere, and ${ }^{238} \mathrm{UO}_{2}$ fuel moves to the center and is removed from the system. The stability limits of standing waves of nuclear burning are investigated. It has been established that for standing waves there are minimum (critical) sizes at which they exist. Mathematical modeling of standing waves using the MCNPX code was carried out and critical sizes of standing waves of various symmetries were determined.

\section{INTRODUCTION}

In recent years, much attention has been paid to such a kind of nuclear burning wave [1] as a standing wave of nuclear burning in a moving fissile medium [2, 3]. The characteristics of these waves and the conditions of their existence were studied; the advantages of standing waves over traveling waves were analyzed [4-6]. However, most of the results are numerical, which complicates the analysis of the properties of such systems. In this paper, for simple analytical models, we study the stability of standing burning waves in systems with external control at the boundaries of the regions of their existence. The existence of minimal (critical) sizes of standing burning waves is shown for one-dimensional, cylindrical, and spherical geometry. Using the MCNPX code [7], mathematical modeling of nuclear burning waves in $\mathrm{UO}_{2}$-based systems is carried out for onedimensional, cylindrical, and spherical cases. It is established that for each geometry there is a minimum permissible size of a standing wave. The numerical values of the critical sizes of standing waves of onedimensional, cylindrical, and spherical symmetry are determined in $\mathrm{UO}_{2}$-based systems.

\section{ONE-DIMENSION BURNING WAVE EQUATIONS OF KINETICS IN A MOVING MEDIUM}

Let us consider the process of nuclear burning in a medium based on $\mathrm{UO}_{2}$ moving with a constant speed $V$ relative to a fixed coordinate system $x, y, z$. The burning process takes place in two stages: at the first stage, neutron capture by ${ }^{238} \mathrm{U}$ nuclei causes chain of nuclear transformations ${ }^{238} \mathrm{U}+\mathrm{n}={ }^{239} \mathrm{U} \rightarrow{ }^{239} \mathrm{~Np} \rightarrow{ }^{239} \mathrm{Pu}$, and at the second stage, fission of ${ }^{239} \mathrm{Pu}$ nuclei with neutron emission occurs. The burning wave moves in the material at a speed of $v$, moreover, the first process occurs mainly at the leading edge of the wave, and the fission process occurs in the central and rear parts of the wave. If the medium velocity $V$ and the wave velocity in the medium $v$ are equal in magnitude and opposite in direction, then a standing burning wave is realized.

The equations describing the standing nuclear burning waves of one-dimensional, cylindrical, and spherical symmetries in systems with external control were obtained in $[4,5,8]$. Scalar neutron flux density in the moving coordinate system $x^{\prime}, y^{\prime}, z^{\prime}$ can be characterized by the following equation:

$$
-D \Delta \Psi+\left(v \Sigma_{f}-\Sigma_{a}\right) \Psi+S=0,
$$

where $\Sigma_{f}-$ and $\Sigma_{a}$ - are the macroscopic cross sections for fission and absorption of neutrons; $D$ is the neutron diffusion coefficient; $v$ is the number of fission neutrons; $S$ is the term describing the feedback and the automatic control of the reactor, which we take in the form: $S=-\rho v \Sigma_{f} \Psi$, where $\rho$ - reactivity excess for the system (excluding feedbacks).

We replace the coordinates $x^{\prime}$ with new variable proportional to the neutron flux in the materials under:

$$
\varphi\left(x^{\prime}\right)=\sigma_{a} \int_{-\infty}^{t} \Psi\left(x^{\prime}, t^{\prime}\right) d t^{\prime}=\sigma_{a} / V \int_{x^{\prime}}^{\infty} \Psi\left(x_{1}^{\prime}\right) d x_{1}^{\prime},
$$

where $\sigma_{a}$ is the microscopic cross section for neutron absorption. After this, equation (1) will be simplified as:

$$
\frac{D \sigma_{a}^{2}}{2 V^{2}} \frac{d^{2} \Psi^{2}}{d \varphi^{2}}+v(1-\rho) \Sigma_{f}-\Sigma_{a}=0 .
$$

The boundary conditions for the functions $\Psi(\varphi)$ have the form:

$$
\Psi(0)=0, \Psi(\chi)=0,
$$

where $\chi=\frac{\sigma_{a}}{V} \int_{-\infty}^{\infty} \Psi\left(x_{1}\right) d x_{1}$ is the maximum neutron fluence achieved in the material after passing the region of nuclear burning. Equation (3) should be supplemented by equations of the balance of isotope concentrations in the chain ${ }^{238} \mathrm{U} \rightarrow{ }^{239} \mathrm{U} \rightarrow{ }^{239} \mathrm{~Np} \rightarrow{ }^{239} \mathrm{Pu}$. In [9] a stationary solution of equation (3) was obtained:

$$
\Psi^{2}(\varphi)=\frac{2 n_{0} V^{2}}{D \sigma_{a}} f(\varphi)
$$

Here $f(\varphi)=\beta \varphi^{2}+(1-2 \beta-q) \varphi+(1-2 \beta-2 q)\left(e^{-\varphi}-1\right)-q e^{-\varphi} \varphi$, $n_{0}$ is the initial concentration of ${ }^{238} \mathrm{U}$, and the parameter $\beta$ defined by the formula: 


$$
\beta=\sigma_{c} \sigma_{f} \sigma_{89} / \sigma_{a}^{3}
$$

Here $\sigma_{c}$ is the microscopic cross section for neutron absorption by ${ }^{238} \mathrm{U},{ }^{239} \mathrm{Pu}$ nuclei and fission products, $\sigma_{f}$ is the microscopic fission cross section for ${ }^{239} \mathrm{Pu}$ nucleus, and $\sigma_{89}$ is the cross section for transmutation of ${ }^{238} \mathrm{U}$ into ${ }^{239} \mathrm{Pu}$.

The maximum fluence $\chi$ implicitly defined by the expression:

$$
\beta=\frac{\left(e^{-\chi}-1\right)^{2}-\chi^{2} e^{-\chi}}{\chi^{2}\left[(1+\chi) e^{-\chi}-1\right]+2\left(\chi+e^{-\chi}-1\right)^{2}},
$$

and the parameter $q$ - following formula:

$$
q=\frac{2 \beta \chi-(1-2 \beta)\left(e^{-\chi}-1\right)}{1-(1+\chi) e^{-\chi}} .
$$

System reactivity margin $\rho$ (excluding feedback), necessary for the existence of a stationary solution is determined by the expression:

$$
\rho=\frac{\sigma_{a}^{2}}{\sigma_{f} \sigma_{89} v}(c-q),
$$

where $c=v \frac{\sigma_{f} \sigma_{89}}{\sigma_{a}^{2}}-\frac{\sigma_{89}}{\sigma_{a}}+2 \beta$.

We introduce the dimensionless variables:

$$
\xi=\sqrt{\frac{2 \sigma_{a} n_{0}}{D}} x ; \psi(\xi)=\frac{\Psi(x)}{V} \sqrt{\frac{D \sigma_{a}}{2 n_{0}}},
$$

then formulas (2) and (6) will take the form:

$$
\psi=\sqrt{f(\varphi)} \text { and } \xi=-\int_{\chi / 2}^{\varphi} \frac{d \varphi^{\prime}}{\sqrt{f\left(\varphi^{\prime}\right)}} .
$$

In Fig. 1 the dependences of $\psi(\xi)$ and $\varphi(\xi)$ on the dimensionless coordinate $\xi$, obtained by formulas (11), are shown.

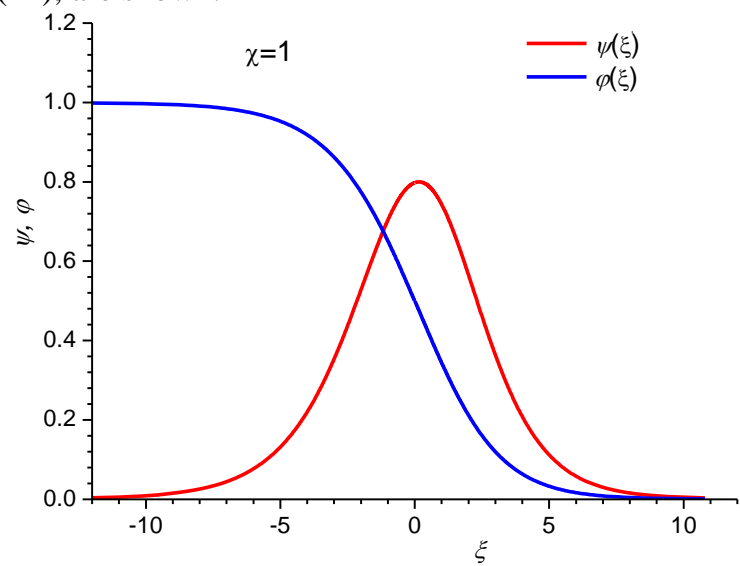

Fig. 1. The density functions of the neutron flux $\psi(\xi)$ and fluence $\varphi(\xi)$ at $\chi=1$

\section{STANDING BURNING WAVES IN THE ONE-DIMENSIONAL CASE}

Consider the process of nuclear burning in a medium moving from two sides to the origin with a constant speed $V$, and the material that goes to the origin is continuously removed from the reactor, and the speed $V$ is chosen so that the burning wave is at rest. Such a system can be described by the previous equations (1-3) in the half-space $x \geq 0$ with mirror boundary conditions. The solution of equation (3) has the same form (5):

$$
\Psi^{2}(\varphi)=\frac{2 n_{0} V^{2}}{D \sigma_{a}} f\left(\varphi, q_{0}\right)
$$

where

$f\left(\varphi, q_{0}\right)=\beta \varphi^{2}+\left(1-2 \beta-q_{0}\right) \varphi-q_{0} e^{-\varphi} \varphi+\left(1-2 \beta-2 q_{0}\right)\left(e^{-\varphi}-1\right)$ and

$\chi_{0}=\frac{\sigma_{a}}{V} \int_{0}^{\infty} \Psi\left(x^{\prime}\right) d x^{\prime}-$ fluence in the discharged fuel.

System reactivity margin $\rho$ is determined by the equation:

$$
\rho=\frac{\sigma_{a}^{2}}{\sigma_{f} \sigma_{89} \nu}\left(c-q_{0}\right) .
$$

Fig. 2 shows the profiles of the density of flux in standing burning waves for a number of $\chi_{0}$ values. As can be seen from Fig. 2, a standing wave is a bound state of two waves traveling in opposite directions in media moving towards them.

A condition for the existence of a standing burning wave is the presence of excessive reactivity in the system $\rho \geq 0$, which is suppressed by negative external feedback. From relation (13) we obtain the inequality $c \geq q_{0}$ or

$$
c>\frac{2 \beta \chi_{0}-(1-2 \beta)\left(e^{-\chi_{0}}-1\right)}{1-\left(1+\chi_{0}\right) e^{-\chi_{0}}}
$$

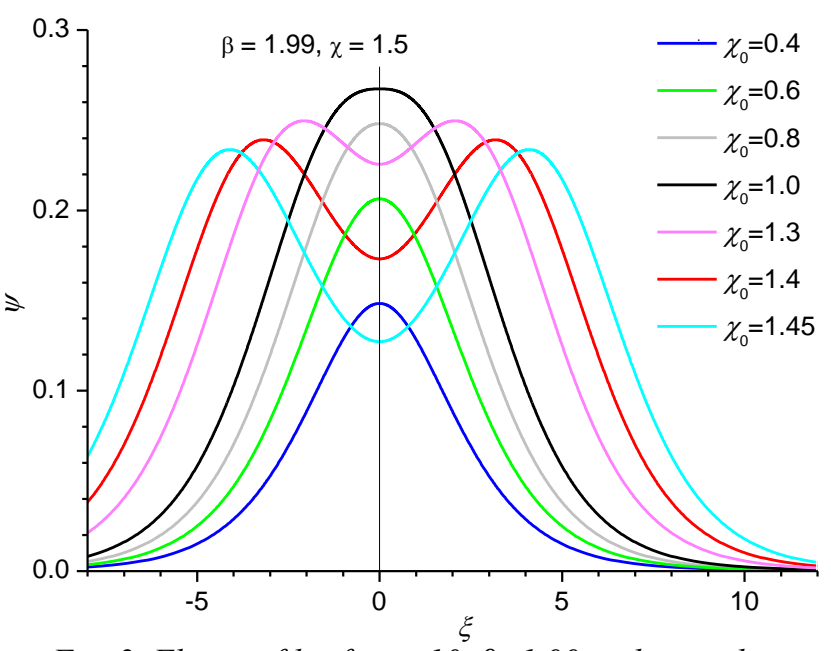

Fig. 2. Flux profiles for $c=10, \beta=1.99$ and a number of values $\chi_{0}$

Inequality (14) holds for $\chi_{0}>\chi_{\min }$, where $\chi_{\min }(c)$ is the minimum allowable dose in burned up fuel for which a stationary solution to the problem still exists. The dependence $\chi_{\min }(c)$ is shown in Fig. 3 for the value $\beta=1.99$. A standing burning wave exists in the shaded area.

Knowing the profile of the burning wave (see Fig. 2 ), one can determine the characteristic size of the standing wave $d_{1 / 2}$ (wave size at half its height). 


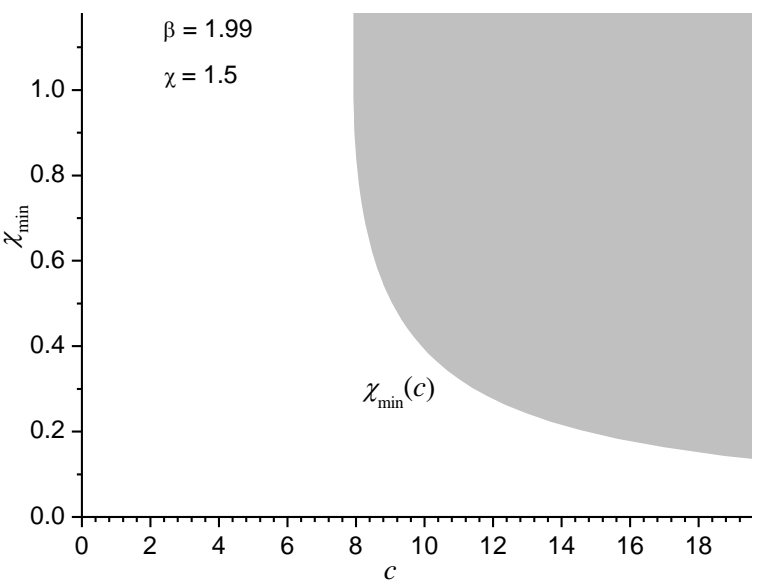

Fig. 3. The dependence of the minimum allowable value offluence $\chi_{\min }(c)$ on parameter $c$

In Fig. 4 solid lines depict the dependences of the sizes of standing waves $d_{1 / 2}$ on the magnitude of the fluence in the unloaded fuel $\chi_{0}$ for materials with $\beta=1$ and $\beta=2$ for $c=10$.

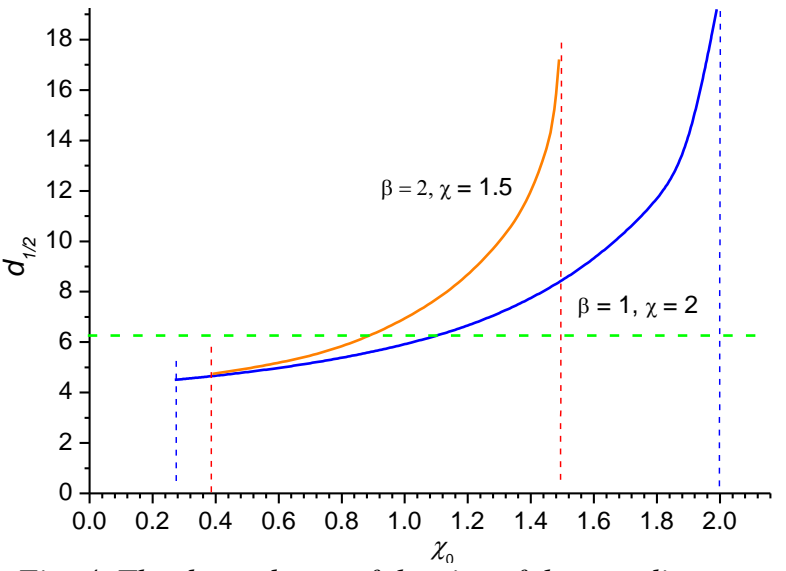

Fig. 4. The dependence of the size of the standing wave

$d_{1 / 2}$ on the magnitude of the fluence $\chi_{0}$

In Fig. 4, the horizontal dashed line shows the size of the corresponding traveling wave in infinite space.

Fig. 4 shows that the minimum permissible dose $\chi_{\min }$ corresponds to the minimum standing wave size $d_{\text {crit }}$. Thus, for given values $c$ and $\beta$ a stable standing burning wave can exist only if its size exceeds the critical value $d_{\text {crit }}$ (Fig. 5), and standing waves with dimensions smaller than critical do not exist.

\section{SIMULATION OF ONE-DIMENSIONAL BURNING WAVES}

The calculation model is a ${ }^{238} \mathrm{U}$ cylinder with a radius of 30 and $120 \mathrm{~cm}$ length with mirror boundary conditions. The profiles of the standing burning waves along the cylinder axis are plotted in Fig. 6, which shows the values $k_{\text {eff }}$ and the corresponding wave sizes at half its height $r_{1 / 2}$. The value $k_{\text {eff }}=1$ corresponds to the critical size $\left\langle r_{\text {crit }}\right\rangle=21.2 \mathrm{~cm}$.

The dependence of $k_{\text {eff }}$ of the standing burning wave on its size $r_{1 / 2}$ is shown in Fig. 7, from which it follows that the critical size of a one-dimensional standing wave corresponds to $21.2 \mathrm{~cm}$.

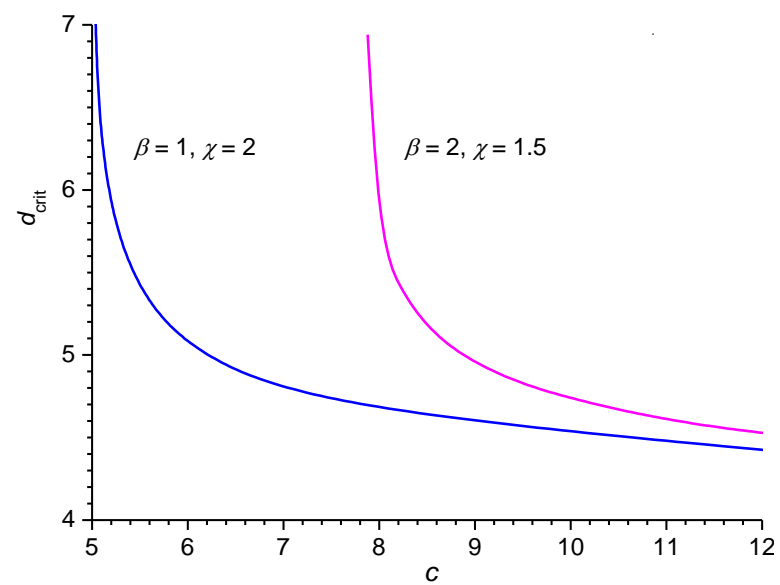

Fig. 5. The critical sizes of standing waves $d_{\text {crit }}$ depending on the parameters $c$ and $\beta$

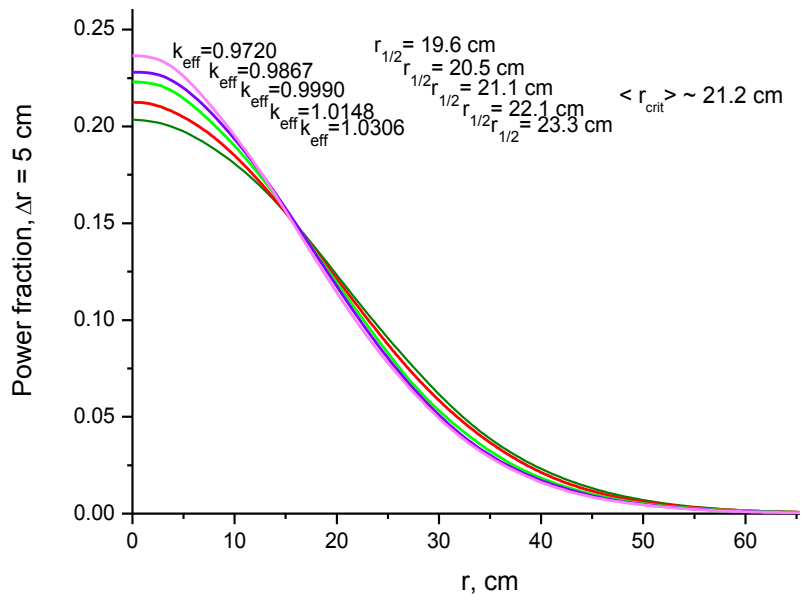

Fig. 6. Profiles of standing burning waves of various sizes

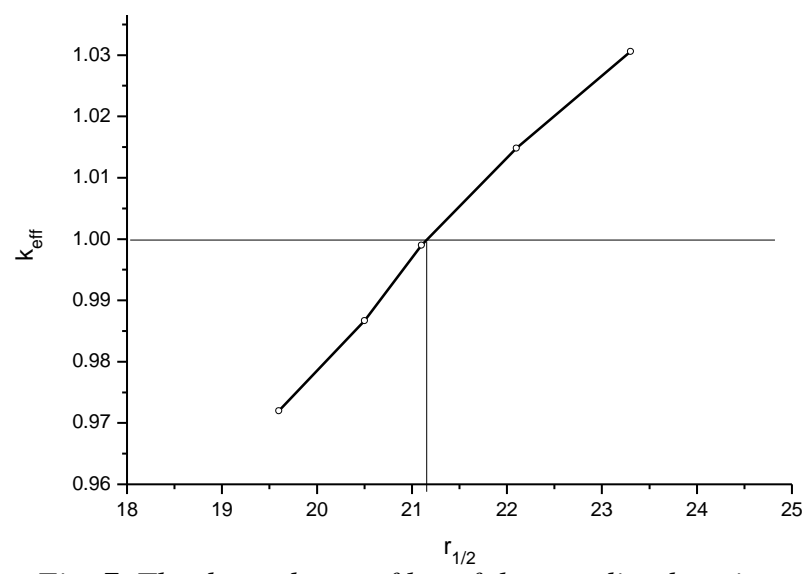

Fig. 7. The dependence of $k_{\text {eff }}$ of the standing burning wave on its dimensions at half height $r_{1 / 2}$

THE CRITICAL DIMENSIONS OF A ONEDIMENSIONAL STANDING BURNING WAVES

Fig. 8 shows profiles of one-dimensional standing burning waves near a critical size.

Thus, the total minimum (critical) size of a onedimensional standing burning wave in $\mathrm{UO}_{2}$ is $d_{\text {crit }}=2\left\langle r_{\text {crit }}\right\rangle=42.4 \mathrm{~cm}$. 


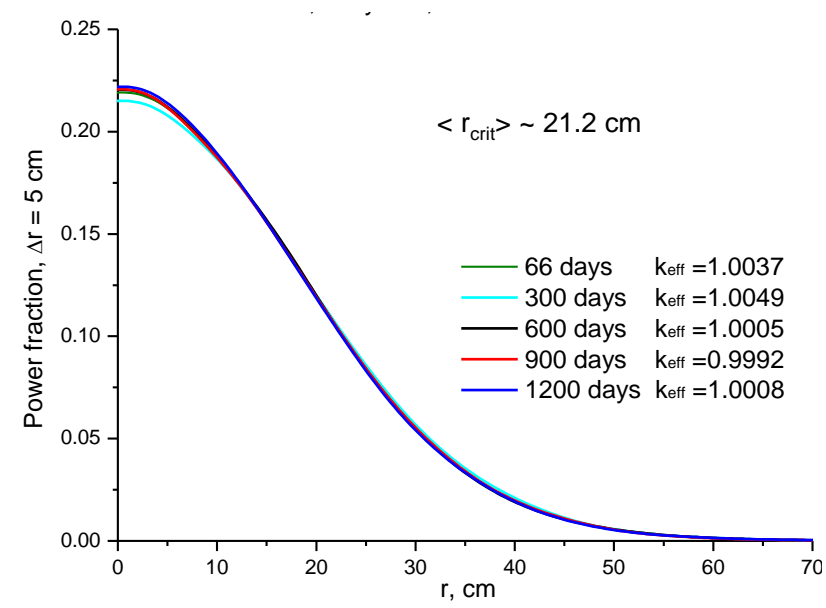

Fig. 8. Profiles of standing burning waves near a critical size

\section{STANDING BURNING WAVE OF A CYLINDRICAL FORM}

Consider a cylindrical reactor in which nuclear burning propagates radially from the axis, and the ${ }^{238} \mathrm{U}$ fuel (which we consider to be an incompressible medium) continuously moves from infinity towards the axis with a speed $V(r)=V_{R} R / r$. Material approaching the axis is removed from the system. In this case, equation (1) takes the form:

$$
-\frac{D}{r} \frac{d}{d r}\left(r \frac{d \Psi}{d r}\right)+\left(v \Sigma_{f}-\Sigma_{a}\right) \Psi+S=0,
$$

with boundary conditions:

$$
\Psi(\infty)=0, d \Psi(0) / d r=0 .
$$

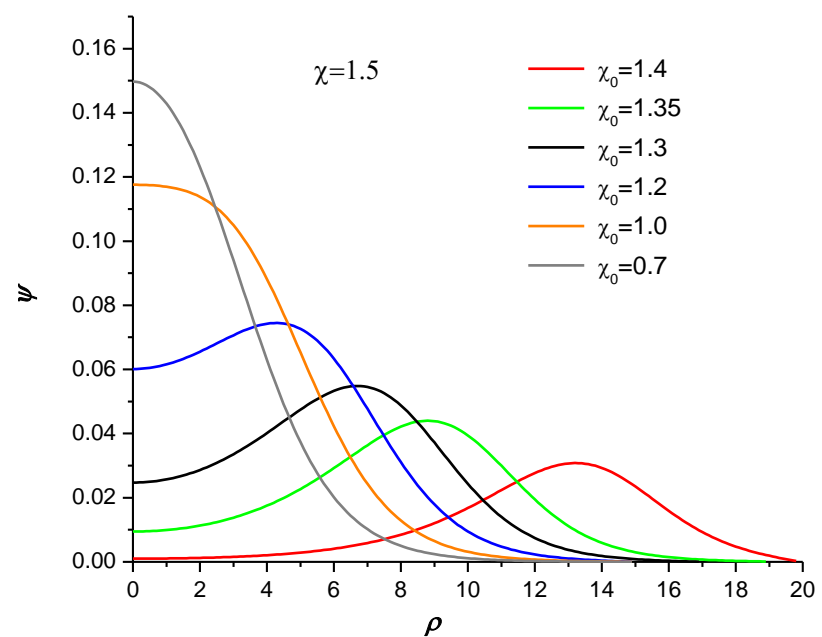

Fig. 9. Profiles of neutron fluxes in cylindrical standing waves at large values of $\chi_{0}$ for $c=10, \beta=2$ and $\chi=1.5$

By substitution $\varphi(r)==\sigma_{a} / V_{R} R \int_{r}^{\infty} r^{\prime} \Psi\left(r^{\prime}\right) d r^{\prime}$ equation (15) can be reduced to the following form [5]:

$$
\frac{D \sigma_{a}}{2 n_{0} V_{R}^{2}} \frac{r^{2}(\phi)}{R^{2}} \frac{d \Psi^{2}}{d \phi}=f_{1}(\phi),
$$

where $f_{1}(\varphi)=2 \beta \varphi-\left(1-2 \beta-q_{0}\right)\left(e^{-\varphi}-1\right)+q_{0} \varphi e^{-\varphi}$.

Numerical solutions of equation (17) are shown in Fig. 9 using dimensionless variables:

$$
\rho=\sqrt{\frac{2 \sigma_{a} n_{0}}{D}} r \text { and } \psi=\frac{D \Psi}{n_{0} V_{R} R} .
$$

\section{THE EXISTENCE REGION OF STANDING CYLINDRICAL BURNING WAVES}

The condition for the existence of a standing cylindrical burning wave is determined by the same relation $c \geq q_{0}$, as for a standing plane wave (14). As a result, we have the same state diagram as in Fig. 3. Standing waves exist in the area $\chi_{0}>\chi_{\min }(c)$. The minimum allowable integral neutron flux $\chi_{\min }$ in the fuel with the given values of $c$ and $\beta$ is determined from the equation:

$$
c=\frac{2 \beta \chi_{\min }-(1-2 \beta)\left(e^{-\chi_{\min }}-1\right)}{1-\left(1+\chi_{\min }\right) e^{-\chi_{\min }}} .
$$

The functions $\chi_{\min }(c)$ for a cylindrical and for a plane standing burning wave coincide.

\section{DIMENSIONS OF A CYLINDRICAL STANDING WAVE}

The solid line in Fig. 10 shows the dependence of the size of the standing waves $d_{1 / 2}$ (wave diameter at half its height) on the maximum fluence $\chi_{0}$ in the material with $\beta=2$.

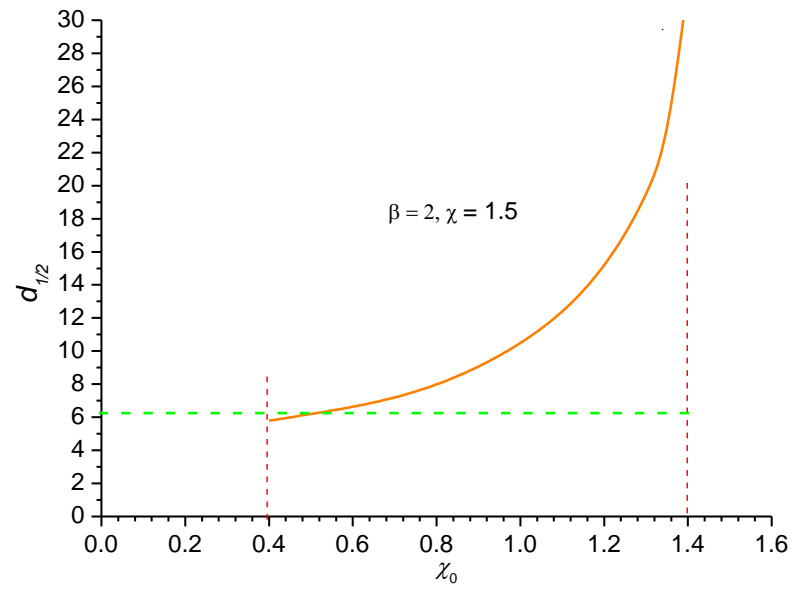

Fig. 10. The dependence of the size of the standing wave $d_{1 / 2}$ on the magnitude of the fluence $\chi_{0}$

The horizontal dashed line in Fig. 10 shows the size of a traveling wave in infinite space.

\section{THE CRITICAL SIZE OF A STANDING CYLINDRICAL WAVE}

The dependence of the dimensions of the cylindrical standing wave $d_{1 / 2}$ on the fluence $\chi_{0}$ is shown in Fig. 11; it differs a little from the corresponding dependence in Fig. 4, however, the same value of the critical fluence $\chi_{\text {min }}$ is observed on them, below which a standing burning wave does not exist.

For standing cylindrical burning waves with given values of $c$ and $\beta$ there is also a critical size $d_{\text {crit, }}$, less than which they do not exist. 


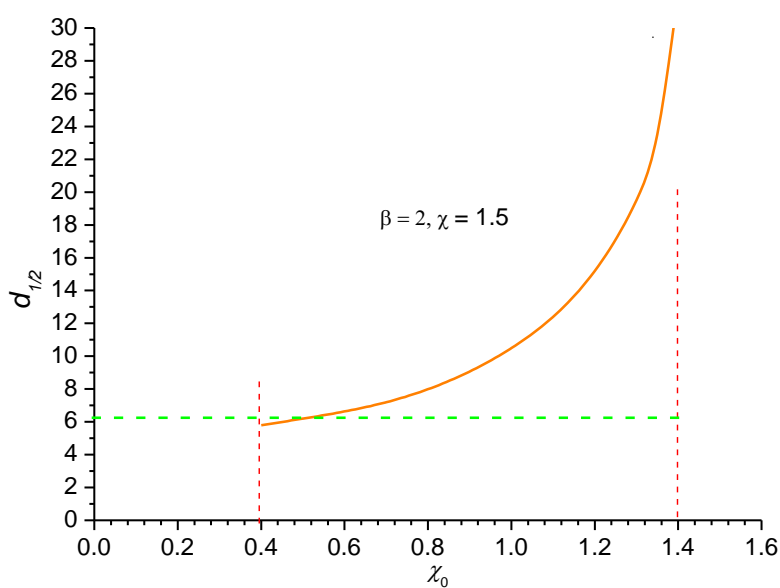

Fig. 11. Dependence of the sizes of a cylindrical standing wave $d_{1 / 2}$ on the fluence $\chi_{0}$

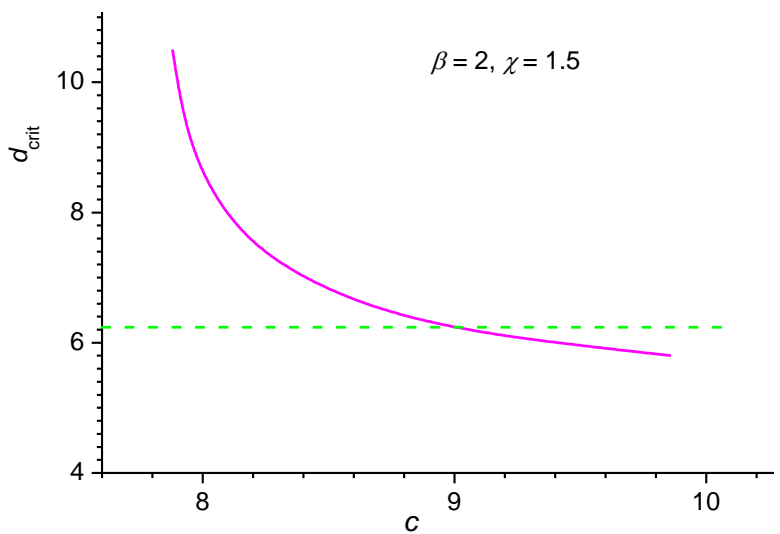

Fig. 12. Dependence of the critical size of cylindrical standing wave $d_{\text {crit }}$ on $c$ at $\beta=2$

Fig. 12 shows the dependence of the critical size of a cylindrical standing wave $d_{\text {crit }}$ on the value of the parameter $c$ at $\beta=2$; the horizontal dashed line shows the width of the traveling wave in infinite space in the material with the same values of $c$ and $\beta$.

\section{SIMULATION OF CYLINDRICAL BURNING WAVES}

The calculation model is a ${ }^{238} \mathrm{UO}_{2}$ cylinder having a radius of $2 \mathrm{~m}$ and a height of $20 \mathrm{~cm}$ with mirror boundary conditions. The profile of a standing burning wave, which remains motionless for 1000 days, is shown in Fig. 13

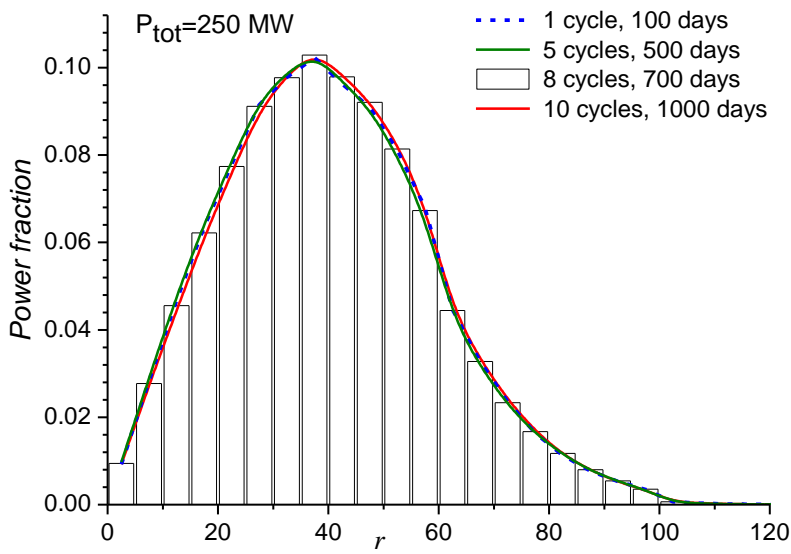

Fig. 13. Standing cylindrical burning wave

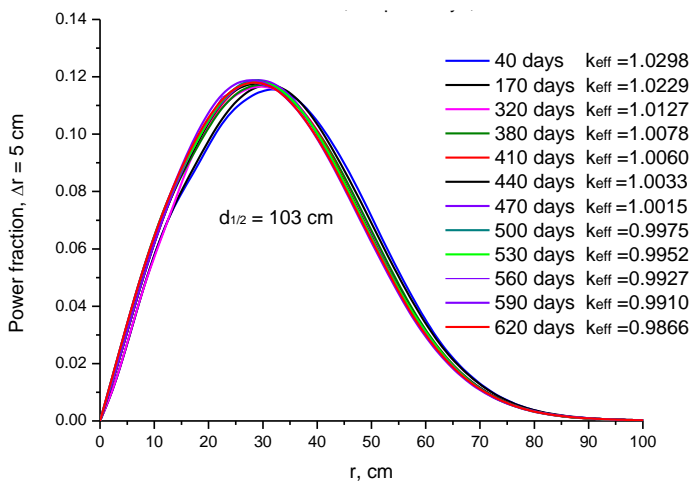

Fig. 14. Simulation results of cylindrical burning waves near the critical diameter

From the simulation results presented in Fig. 14 it follows that the critical diameter of the cylindrical standing burning wave in $\mathrm{UO}_{2}$ is $d_{\text {crit }}=103 \mathrm{~cm}$.

\section{STANDING SPHERICAL WAVE OF NUCLEAR BURNING}

Consider a spherical reactor in which nuclear burning propagates radially from the center, and ${ }^{238} \mathrm{UO}_{2}$ fuel continuously moves from infinity to the center of the reactor at a speed $V(r)=V_{R}(R / r)^{2}$. Material approaching the center is removed from the system. The neutron kinetics in a spherical wave is described by the equation

$$
-\frac{D}{r^{2}} \frac{d}{d r}\left(r^{2} \frac{d \Psi}{d r}\right)+\left(v \Sigma_{f}-\Sigma_{a}\right) \Psi+S=0,
$$

where $D$ are the neutron diffusion coefficients and $\Psi(\infty)=0, d \Psi(0) / d r=0$ are the boundary conditions.

Instead of the coordinate $r$, we introduce in (19) the dimensionless fluence $\varphi(r)$ :

$$
\begin{array}{r}
\varphi(r)=\frac{\sigma_{a}}{V_{R} R^{2}} \int_{r}^{\infty} \Psi\left(r^{\prime}\right) r^{\prime 2} d r^{\prime}, \\
\text { then } \frac{D \sigma_{a}}{2 n_{0} V_{R}^{2}} \frac{r^{4}(\varphi)}{R^{4}} \frac{d \Psi^{2}}{d \varphi}=f_{1}\left(\varphi, q_{0}\right),
\end{array}
$$

where $f_{1}\left(\varphi, q_{0}\right)=2 \beta \varphi-\left(1-2 \beta-q_{0}\right)\left(e^{-\varphi}-1\right)+q_{0} \varphi e^{-\varphi}$ and, as before, $q_{0}(\beta)$ is described by formula (12), and $\chi_{0}$ is a free parameter.

\section{CALCULATION OF A STANDING SPHERICAL WAVE PROFILE}

Numerical solutions of equation (21) in variables $\rho=\sqrt{\frac{2 \sigma_{a} n_{0}}{D}} r$ and $\omega=\frac{D \Psi}{n_{0} V_{R} R^{2}} \sqrt{\frac{D}{2 n_{0} \sigma_{a}}}$. are shown in Fig. 15.

The condition for the existence of a standing spherical burning wave is determined by the same relation $c \geq q_{0}$ (see (14)).

\section{DIMENSIONS OF A SPHERICAL STANDING WAVE}

Fig. 16 shows the dependence of the dimensions of a spherical standing wave $d_{1 / 2}$ on fluence $\chi_{0}$. As can be seen from this dependence, there is a critical fluence below which a standing burning wave does not exist in this material. 


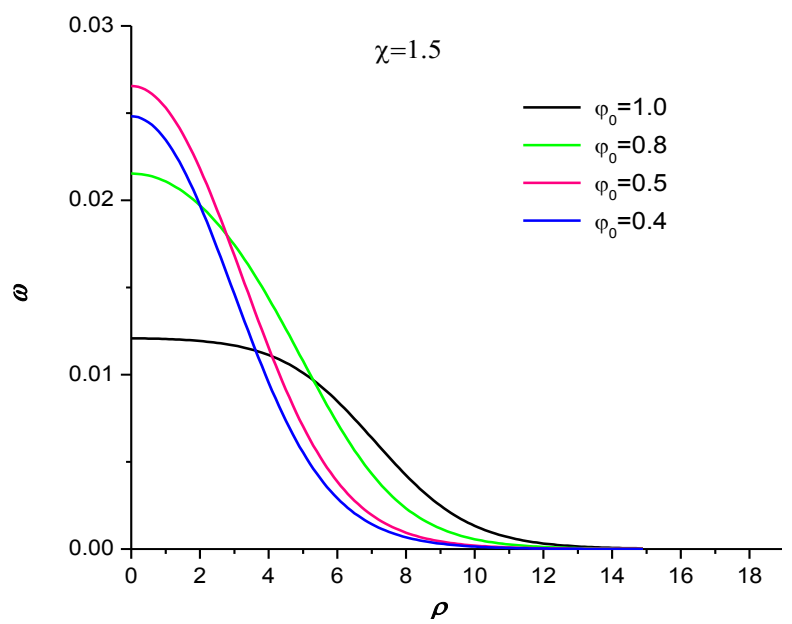

Рис. 15. Профили нейтронных потоков в сферических стоячих волнах для с $=10, \beta=2$

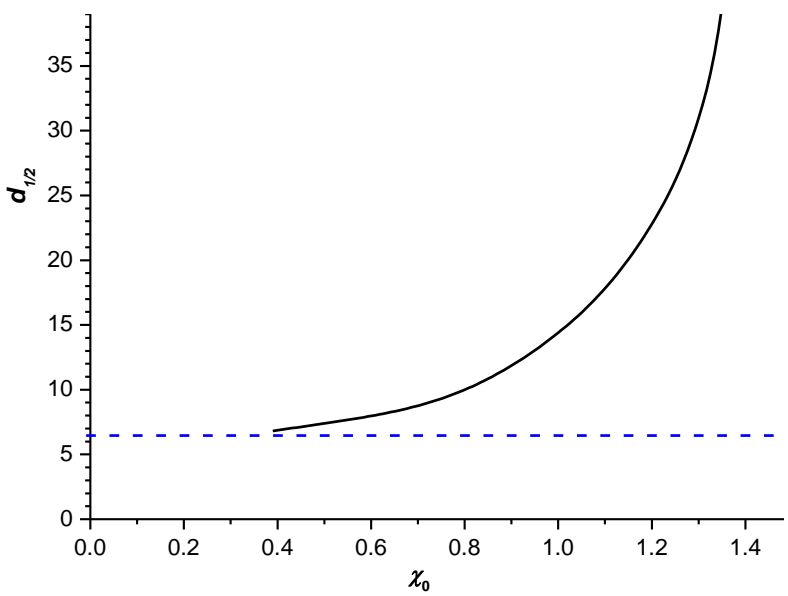

Fig. 16. The dependence of the size of a spherical standing wave $d_{1 / 2}$ on the fluence $\chi_{0}$ for $c=10, \beta=2$

\section{THE CRITICAL SIZE OF A SPHERICAL STANDING WAVE}

For standing spherical burning waves with given values of $c$ and $\beta$ just as for plane and cylindrical waves, there exists a critical size $d_{\text {crit }}$, less than which they do not exist.

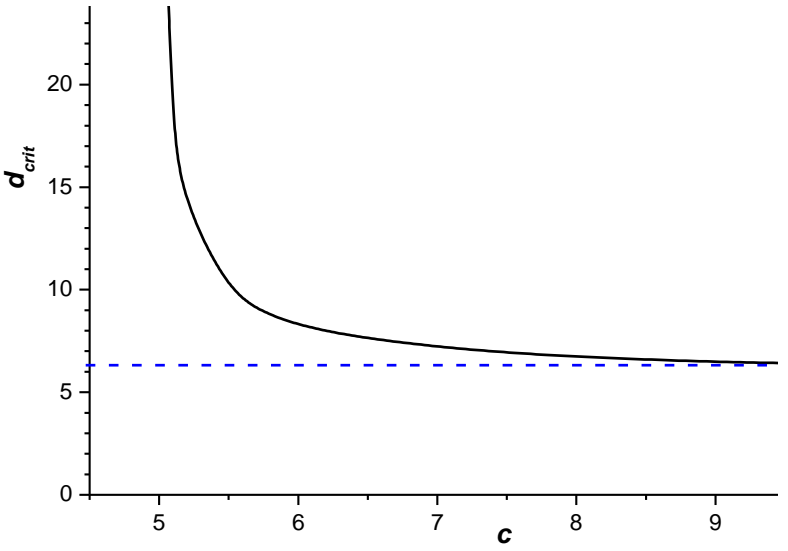

Fig. 17. The dependence of the critical size of a spherical standing wave $d_{\text {crit }}$ on $c$ at $\beta=2$

Fig. 17 shows the dependence of the critical size of a spherical standing burning wave $d_{\text {crit }}$ on the value of the parameter $c$ at $\beta=2$. For spherical standing waves, the critical wave size $d_{\text {crit }}$ is a more significant limitation than for standing cylindrical and plane waves.

\section{SIMULATION OF SPHERICAL BURNING WAVES}

To simulate a spherical burning wave, a sphere of ${ }^{238} \mathrm{UO}_{2}$ with a radius of $2 \mathrm{~m}$ was used. Profiles of standing burning waves are shown in Fig. 18, at which values of the $k_{\text {eff }}$ and the wave diameter at half its height $\left\langle d_{\text {crit }}\right\rangle=104 \mathrm{~cm}$ corresponding to $k_{\text {eff }}=1$ are given.

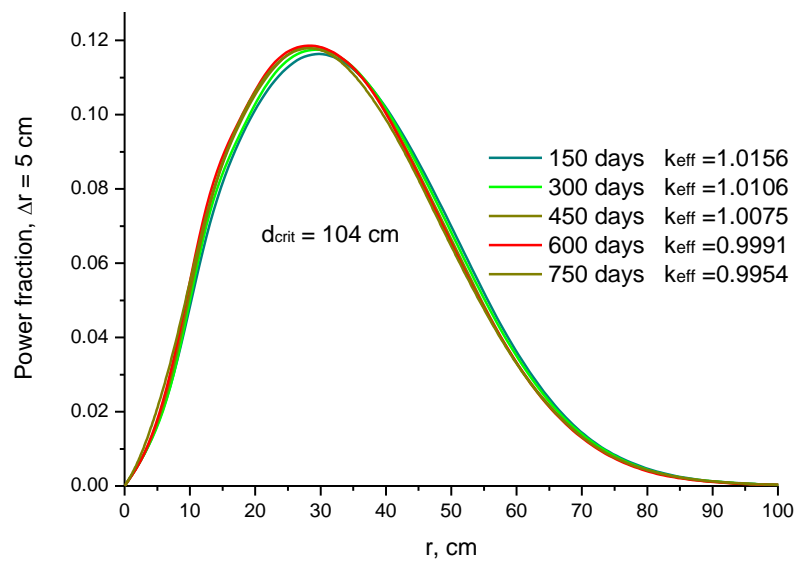

Fig. 18. Simulation results of spherical standing burning waves near a critical size

So, the minimum (critical) diameter of a spherical standing burning wave in $\mathrm{UO}_{2}$ is $d_{\text {crit }}=104 \mathrm{~cm}$.

\section{CONCLUSIONS}

- Nuclear burning waves exist not only in onedimensional geometry, but also in systems with cylindrical and spherical symmetry.

- The theory of standing nuclear burning waves in systems with external control in moving fuel media with plane, cylindrical and spherical symmetries is proposed.

- Criteria were established for the existence of standing nuclear burning waves in reactors with different core symmetries, and state diagrams of such reactors were constructed.

- The critical (minimum permissible) sizes of standing waves of various symmetries are determined.

\section{REFERENCES}

1. L.P. Feoktistov. Neutron-fission wave // Rep. Academy Sciences of the USSR. 1989, v. 309, p. 864867.

2. T. Ellis, R. Petroski. Traveling-Wave Reactors: A Truly Sustainable and Full-Scale Resource for Global Energy Needs // Proceedings of ICAPP '10, San Diego, CA, USA, June 13-17, 2010, 10189 p.

3. TERRAPOWER, LLC Traveling Wave Reactor Develop Program Overview // http://dx.doi.org/10.5516/NET.02.2013.520

4. Yu.Y. Leleko, V.V. Gann, A.V. Gann. Computer Simulation of Stationary Burning Wave Reactor // 4th International Conference "Computer modelling in hightech" (CMHT-Kharkov 2016), May 26-31, 2016, Kharkov, Ukraine, p. 206

5. Yu.Y. Leleko, V.V. Gann, A.V. Gann. Nuclear reactor on cylindrical standing burning wave with an external negative reactivity feedback // Problems of 
Atomic Science and Technology. 2017, N 2(108), p. 138-143.

6. V.V.Gann, Yu.Y.Leleko, A.V.Gann Computer simulation of nuclear reactor on cylindrical standing burning wave // Proceedings of NUCLEAR 2017 the 10th International Conference on Sustainable Development through Nuclear Research and Education, Pitesti, 2017, May 24-26, p. 161-168.

7. MCNPX User's Manual Version 2.5.0, April. 2005 LA-CP-05-0369.
8. Yu.Y. Leleko, V.V. Gann, A.V. Gann. Spherical standing burning wave with an external automatic reactivity control // Problems of Atomic Science and Technology. 2019, N 5(123), p. 18-24.

9. V.V. Gann, A.V. Gann. Benchmark on traveling wave fast reactor with negative reactivity feedback obtained with MCNPX code // 4 International Conference "Current Problems in Nuclear Physics and Atomic Energy” (NPAE-Kyiv 2012), September 3-7, 2012, Kyiv, Ukraine. Proceedings Part II, p. 421-425.

Article received 19.03.2020

\title{
КРИТИЧЕСКИЕ РАЗМЕРЫ СТОЯЧИХ ВОЛН ЯДЕРНОГО ГОРЕНИЯ В СИСТЕМАХ С ВНЕШНИМ УПРАВЛЕНИЕМ
}

\author{
Ю.Я. Лелеко, В.В. Ганн
}

Развита теория стоячих волн ядерного горения в реакторах, имеющих плоскую, цилиндрическую или сферическую форму активной зоны. Сферическая стоячая волна возникает в случае, когда ядерное горение распространяется радиально от центра сферы, а топливо ${ }^{238} \mathrm{UO}_{2}$ двигается к центру и удаляется из системы. Исследованы границы устойчивости стоячих волн ядерного горения. Установлено, что для стоячих волн имеются минимальные (критические) размеры при которых они существуют. Проведено математическое моделирование стоячих волн с помощью кода MCNPX и определены критические размеры стоячих волн различной симметрии.

\section{КРИТИЧНІ РОЗМІРИ СТОЯЧИХ ХВИЛЬ ЯДЕРНОГО ГОРІННЯ В СИСТЕМАХ 3 ЗОВНІШНІМ УПРАВЛІННЯМ}

\author{
Ю.Я. Лелеко, В.В. Ганн
}

Була розвинена теорія стоячих хвиль ядерного горіння в реакторах,маючих плоску, циліндричну та сферичну форму активної зони. Розглянуто сферичний реактор, в якому хвиля ядерного горіння рухається радіально від центру, а паливо - до центру реактора та вилучається із нього. При підживленні такої системи ${ }^{238} \mathrm{UO}_{2}$ в ній може існувати сферична стояча хвиля ядерного горіння. Показано, що для стоячих хвиль існують мінімальні (критичні) розміри, до яких вони існують. Впроваджено чисельне моделювання стоячих хвиль з використанням коду MCNPX та відзначені критичні розміри стоячих хвиль різної симетрії. 
